\title{
Weight Regain after Bariactric Surgery. Endoscopic Suture with Overstitch Use for Gastrointestinal Anastomosis Decrease. Inicial Results: Brasilian Multicenter Study
}

\section{Bruno Queiroz Sander*, Marcelo Pereira Sander, Jimi Scarparo, Felipe Matz, Felipe Ramos, Carlos Henrique Rodrigues Castro, Stephany Roman Farfan, Waldemilson Cleber de Castro Vieira, Hellen Guimarães Sampaio, Edson Portela, Linsmar Dantas Conceição, Diego Paim Carvalho Garcia and Luiz Ronaldo Alberti}

Department of Surgery, Universidade Federal de Minas Gerais - UFMG, Brazil

*Corresponding Author: Bruno Queiroz Sander, Department of Surgery, Universidade Federal de Minas Gerais - UFMG, Brazil.
Received: July 08, 2020

Published: August 12, 2020

(C) All rights are reserved by Bruno Queiroz

Sander., et al.

\section{Abstract}

A new potential treatment option for weight regain after bariatric surgery is endoscopic suturing with the OverStitch system. The aim of this study was to analyze the weight regain after this procedure in patients who underwent bariatric surgery. There was a significant mean reduction in weight and BMI. There was progressively an increase of Total Body Weight Loss percentage. No complications were observed during or after the procedure.

Keywords: Obesity; Gastroplasty; Weight Regain

\section{Introduction}

Obesity is a public health problem with significant implications, individually such as increased comomorbidity and mortality as well as the economic health system. There was a rapid increase in the prevalence of obesity, that since 1975 has nearly tripled, and in 2017-2018 reached a rate of $42.4 \%$. It is pathophysiology is quite complex, and obesity is a serious risk factor for many major chronic illnesses, such as heart disease, type 2 diabetes, câncer and most recently to the worst prognosis in patients infected with $\mathrm{CO}$ VID-19 [1-3].

The endoscopic sleeve gastroplasty (ESG) is a potential treatment option, and has been successfully developed around the world. This technique has been shown to be safe and effective in the treatment of obesity [4-6]. But weight regain has been a constant concern, as reports in literature indicate that rates can reach up to $50 \%$, especially in patients who have under gone bariatric surgery $[1,7,8]$. However, it is not yet clear how weight regain occurs be cause it is avariable that under goes various intrinsic and extrinsic interference sof the individual. Thus, this paper aims to describe the initial results of a long-term clinical study in Brazil.

\section{Methodology}

Three treatment centers for obesity from the main Brazilian capitals participated in this study, Belo Horizonte, São Paulo and Rio de Janeiro. All patients were subjected ESG and instructed on the ethical aspects of the research, between 2017 and 2019, and were followed for a period of 18 months after the procedure by a multidisciplinary team.

Participated in this study sixty-two patients (Forty-two submitted to full-thickness Z-shaped sutures and twenty submitted to full-thickness Z-shaped sutures + Reinforcement). All procedures were performed by the same endoscopist surgeon from each center.

Variables analyzed were weight, BMI (Body mass index), TBWL\% (Total Body Weight Loss percentage) and EWL\% (Excessive Weight Loss). The data were analyzed using the SPSS software. 
Weight Regain after Bariactric Surgery. Endoscopic Suture with Overstitch Use for Gastrointestinal Anastomosis Decrease. Inicial Results: Brasilian Multicenter Study

Analyzes between the follow-up times for the outcome variables were considered significant at $\mathrm{p}<0.05$.

\section{Results}

The sample's mean age was $42.9 \pm 8.7$ years old, and the majority were women (84.4\%). Pre-intervention data: weight: 103.7 $\pm 17.9 \mathrm{~kg}$ and BMI: $36.2 \pm 6.1 \mathrm{~kg} / \mathrm{m}$. A mean of $28.9 \pm 9.3$ bites per suture and $2.1 \pm 0.7$ threads were used in the procedure.

There was a significant mean reduction of $11.9 \pm 5.3 \mathrm{~kg}, 15.2$ $\pm 6.1 \mathrm{~kg}$ and $19.3 \pm 8.9 \mathrm{~kg}$ at 6 months, 12 months and 18 months respectively. A mean reduction of $4.1 \pm 1.5,5.5 \pm 2.1$ and $6.7 \pm 2.5$ points in the BMI para meter was observed for follow-up times of 6 months, 12 months and 18 months, respectively. There was progressively an increase of TBWL\% $=11.3 \pm 3.6,14.6 \pm 3.8$ and 17.7 \pm 4.5 for 6,12 and 18 months respectively. The Excessive Weight Loss was significant at 6 months (EWL\% $=40.4 \pm 13.5$ ), at 12 months $(50.3 \pm 17.7)$ and 18 months at follow-up (56.3 \pm 8.6$)$. No complications were observed during or after the procedure.

\section{Discussion}

The data so far have shown very significant results in relation to the main out come (EWL\%), as this study presented na approximate loss of $50 \%$ of the excesso weight in the first 12 months. There was as light increase in this parameter in later follow-up. Theres hould be pointed out that between one year and a year and a half, the weight loss was kept going on.

Too many patients with doubts about bariatric surgery or ineligible for it, and for them ESG has proven to be a safe and effective option in weight loss [9]. A recent study [10], which evaluated the data published in the literature so far, showed that ESG was superior in all parameters for decreasing and maintaining long-term weight loss when compared to the intragastric balloon method. Our results corroborate the study conducted by Li., et al. (2020) [6] and Hedjoudje., et al. (2020) [11] and Alqahtani., et al. (2019) [12]. The parameter of Total Body Weight Loss percentage was very similar, while for the parameter Excessive Weight Loss our study showed lower percentages, for the periods of six months and one year of follow up.

The weight regain in patients previously submitted to bariatric surgery is a consequence of multiple causes, and among them, we can mention the dilation caused by the consumption of food in bolus, or by the intake of food over time. In these cases the endosco- pic suture is an effective, safe and satisfactory therapeutic option. Studies that evaluate long-term weight regain, after endoscopic suture, in individuals undergoing bariatric surgery, are necessary to make it an option in the management of these cases.

In this initial cut of the study, no complications were observed during or after the procedure. But the literature points out that adverse events can occur, for example pain or nausea requiring hospitalization, upper gastrointestinal bleeding, and peri-gastric leak or fluid collection [10-14].

\section{Conclusion}

Our results showed that the technique is safe and effective in weight loss and in preventing long-term weight regain. These results are due in large part to the multidisciplinar work employed through out the follow-up of these patients.

\section{Bibliography}

1. Endalifer ML and Diress G. "Epidemiology, Predisposing Factors, Biomarkers, and Prevention Mechanism of Obesity: A Systematic Review". Journal of Obesity (2020): 6134362.

2. Uccelli M., et al. "COVID-19 and Obesity: Postoperative Risk in Patients Who Have Undergone Bariatric Surgery. Preliminary Report from High Volume Center in Italy (Lombardy)". Obesity Surgery (2020).

3. Yang J., et al. "Obesity aggravates COVID-19: a systematic review and meta-analysis". Journal of Medical Virology (2020).

4. de Moura DTH., et al. "Endoscopic sleeve gastroplasty in the management of weight regain after sleeve gastrectomy". Endoscopy 52.3 (2020): 202-210.

5. Hourneaux de Moura DT., et al. "Perspectives toward minimizing the adverse events of endoscopic sleeve gastroplasty". Gastrointestinal Endoscopy (2020).

6. Li P., et al. "Efficacy and safety of endoscopic sleeve gastroplasty for obesity patients: a meta-analysis". Surgical Endoscopy 34.3 (2020): 1253-1260.

7. Turicchi J., et al. "Associations between the rate, amount, and composition of weight loss as predictors of spontaneous weight regain in adults achieving clinically significant weight loss: A systematic review and meta-regression". Journal of the International Association for the Study of Obesity 20.7 (2019): 935-946. 
8. Yu Y., et al. "Predictors of weight regain after sleeve gastrectomy: an integrative review". Surgery for Obesity and Related Diseases 15.6 (2019): 995-1005.

9. Wang JW and Chen CY. "Current status of endoscopic sleeve gastroplasty: An opinion review". World Journal of Gastroenterology 26.11 (2020): 1107-1112.

10. Singh S., et al. "Intragastric Balloon Versus Endoscopic Sleeve Gastroplasty for the Treatment of Obesity: a Systematic Review and Meta-analysis". Obesity Surgery 30.8 (2020): 30103129.

11. Hedjoudje A., et al. "Efficacy and Safety of Endoscopic Sleeve Gastroplasty: A Systematic Review and Meta-Analysis". Clinical Gastroenterology and Hepatology 18.5 (2020): 1043-1053 e4.

12. Alqahtani A., et al. "Short-term outcomes of endoscopic sleeve gastroplasty in 1000 consecutive patients". Gastrointestinal endoscopy 89.6 (2019): 1132-1138.

13. King WC., et al. "Weight regain after bariatric surgery: a systematic literature review and comparison across studies using a large reference sample". Surgery for obesity and related diseases: official journal of the American Society for Bariatric Surgery (2020).

14. Mohan BP., et al. "Outcomes of endoscopic sleeve gastroplasty; how does it compare to laparoscopic sleeve gastrectomy? A systematic review and meta-analysis". Endoscopy International Open 8.4 (2020): E558-E65.

\section{Assets from publication with us}

- Prompt Acknowledgement after receiving the article

- Thorough Double blinded peer review

- Rapid Publication

- Issue of Publication Certificate

- High visibility of your Published work

Website: www.actascientific.com

Submit Article: www.actascientific.com/submission.php

Email us: editor@actascientific.com

Contact us: +919182824667 